\title{
A NUMERICAL STUDY OF PRECAST BEAM-COLUMN MOMENT CONNECTIONS UNDER COLUMN REMOVAL SCENARIO
}

\author{
Mariam Ehab ${ }^{1}$, Hamed Salem ${ }^{2}$, MohamedAbdel-Mooty ${ }^{2}$ \\ ${ }^{1}$ Departement of civil Engineering, British University in Egypt \\ ${ }^{2}$ Faculty of Engineering, Cairo University
}

\begin{abstract}
Precast concrete structures become widely used recently due to high quality of manufacturing as well as its good behaviour under gravity .However the most critical part in the precast structures is beam to column connections in precast frame system due to the different variables involved in the assemblages. In this paper a study is carried out on different wet beam column connections under column removal scenario to observe the behaviour of the connections due to progressive collapse. Different column removal locations with different frame arrangements is studied. The Applied Element Method is implemented in the study to construct a 3D detailed model of the studied connections by using Extreme Loading of Structures Software. The performance of the connections is presented in terms beam, column and joint behaviour. Maximum beam deflection, rotation and internal axial force, normal and shear stresses of the connection reinforcement as well as the column behaviour in terms of rotation and internal axial forces are discussed. From the results obtained an enhancement design is suggested for the failed connections and studied its effect in resisting the local failure due to column removal.
\end{abstract}

Keywords: progressive collapse analysis, precast concrete connections, RC corbels, special moment frames, Applied Element Method.

\section{1-Introduction}

In the last few decades, many precast concrete structures encountered partial and total collapse due to accidental events of some structural elements. Ronan point failure took place in 1968 due to a gas explosion. The propagation of failure of the structure due to the local damage of one of the main structural components or its connection is defined as the Progressive collapse.

Few researchers studied the overall behaviour of the precast concrete structure due to column loss scenario. Shi [1] evaluated the threat due to bombing and the progressive collapse of a prototype moment frame precast concrete building designed according to the PCI-seismic design Handbook. The effect of the column removal on the different beams have been investigated and suggestions for enhancing the beam resistance due to column removal has been proposed.

Main et al. [2] conducted a study on both full scale testing and detailed Finite element modelling of a precast concrete moment frame assembly of a 10-story prototype building where failure modes were recorded. Nimse et al [3] and [4] studied different reduced onethird scaled precast wet and dry connections due to column removal. Failure mode and pattern for the studied connections were monitored and their resistance due to column removal were reported.

This current study focuses on the behaviour of one type of precast connections (ordinary moment connection) with different surrounding beam and column arrangement under column 
removal scenario, ordinary. They are picked from a 5-storey prototype precast concrete structure designed according to the ACI recommendations [5]. Different column removal locations were investigated. The connection modelling and analysis are conducted using a non-linear Applied Element Method (AEM) software called Extreme Loading of Structures (ELS), Meguro and TagelDin [6], Salem et al [7]. The behaviour is evaluated in terms of adjoining elements rotation, deflection, axial forces and steel reinforcement normal stresses variation with respect to time.

\section{Applied element method (AEM) [8]}

The Applied Element Method is an innovative modeling method adopting the concept of discrete cracking, Tagel-Din and Meguro [9], [10] and [11]. In Applied Element Method (AEM), the structures are modeled as an assembly of relatively small elements, made by dividing of the structure virtually, as shown in Figure 1.a. The elements are connected together along their surfaces through a set of normal and shear springs. The springs are responsible for transfer of normal and shear stresses, respectively, from one element to another. Springs represent stresses and deformations of a certain volume as shown in Figure 1.b.

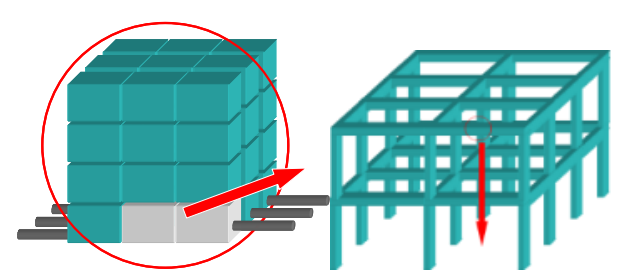

a- Element Generation for AEM

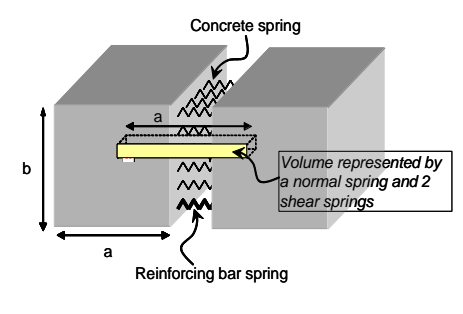

b- Spring distribution and area of influence of each pair of springs

Figure 1 Modeling of structure to AEM

Each single element has 6 degrees of freedom; 3 for translations and 3 for rotations. Relative translational or rotational motion between two neighboring elements cause stresses in the springs located at their common face as shown in Figure 2. These connecting springs represent stresses, strains and connectivity between elements. Two neighboring elements can be separated once the springs connecting them are ruptured.

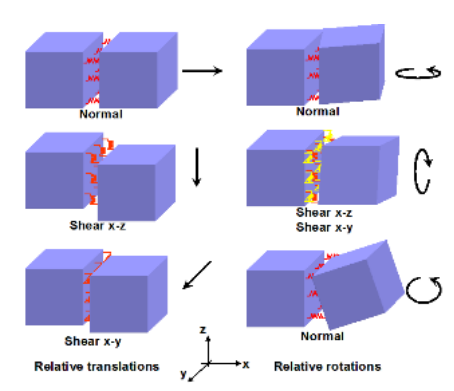

Figure 2: Stresses in springs due to relative displacements

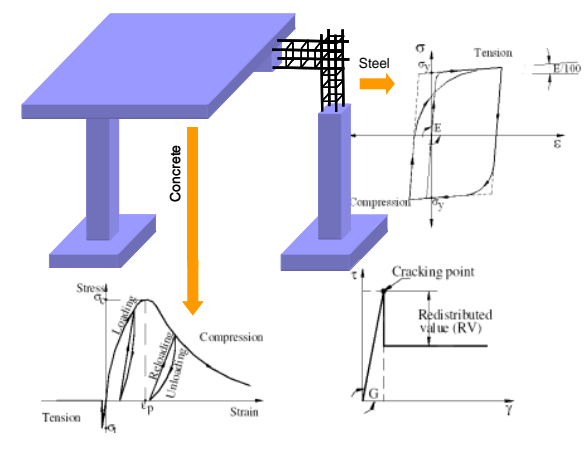

Figure 3: Constitutive models adopted in AEM for concrete and steel.

Fully nonlinear path-dependent constitutive models for reinforced concrete are adopted in the AEM as shown in Figure 3. For concrete in compression, an elasto-plastic and fracture model is adopted, Maekawa [12]. When concrete is subjected to tension, a linear stress strain relationship is adopted until cracking of the concrete springs, where the stresses then drop to 
zero. The residual stresses are then redistributed in the next loading step by applying the redistributed force values in the reverse direction. For concrete springs, the relationship between shear stress and shear strain is assumed to remain linear till the cracking of concrete. Then, the shear stresses drop down as shown in Figure 3. The level of drop of shear stresses depends on the aggregate interlock and friction at the crack surface. For reinforcement springs, the model presented by Ristic [13]. The tangent stiffness of reinforcement is calculated based on the strain from the reinforcement spring, loading status (either loading or unloading) and the previous history of steel spring which controls the Bauschinger's effect. The solution for the dynamic problem adopts implicit step-by-step integration (Newmarkbeta) method Bathe and Chopra [14] [15]. Separated elements may collide with other elements. In that case, new springs are generated at the contact points of the collided elements.

\section{The program validation}

In this section, the ELS software is validated by analyzing the specimens tested by Nimse et al [4].

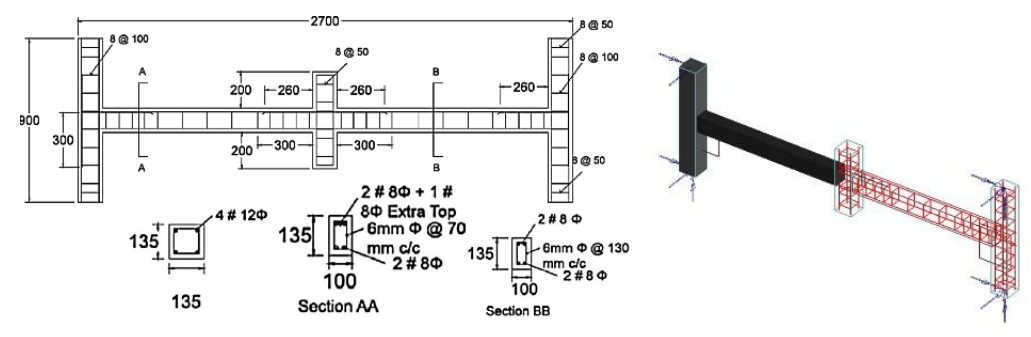

a- Monolithic Specimen

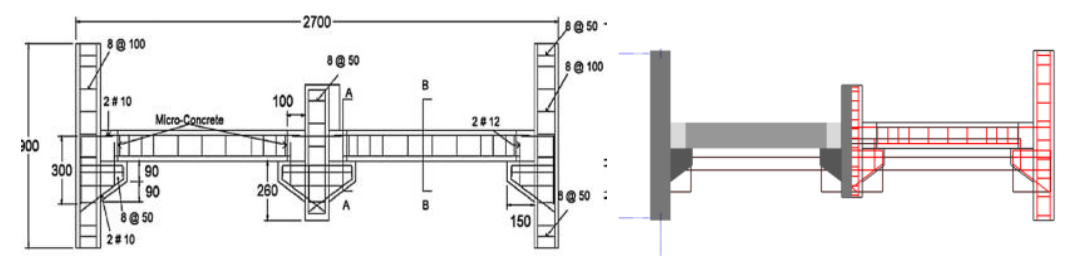

b- PC-CRW Specimen

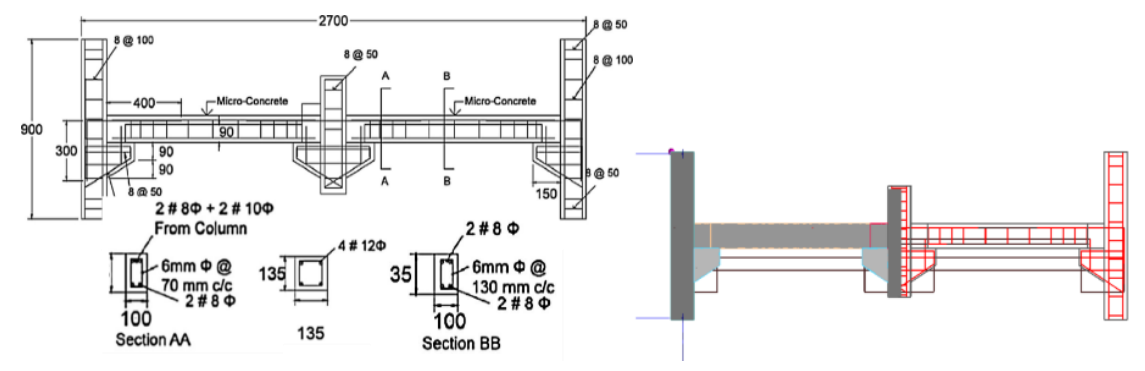

c- PC-CRS Specimen

\subsection{Specimen description and modelling}

Figure 4: Specimen detailing and corresponding ELS models

Three one-third scaled specimens are modelled and detailed using the ELS. The tested specimens are identified as monolithic connection (MC), precast connection of PC-CRW and PC-CRS respectively. The detailing of the tested specimens as well as the ELS models are shown in Figure 4.

\subsection{Analysis of results}

Central deflection versus the applied load is shown in Figure 5. The analytical model shows acceptable results compared to the experimental results as shown in figure 5 . The three specimen shown to have approximately the same load capacity with a slight difference in the downward deformation. 
A NUMERICAL STUDY OF PRECAST BEAM-COLUMN MOMENT CONNECTIONS UNDER COLUMN REMOVAL SCENARIO

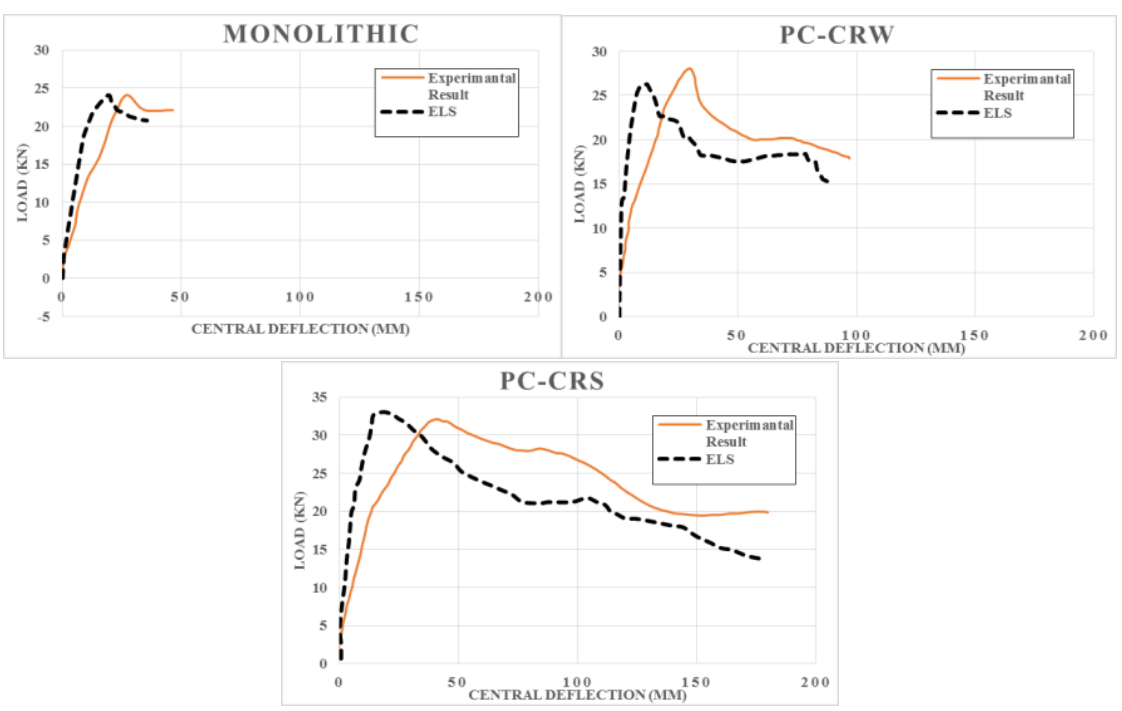

Figure 5: Load versus central deflection.

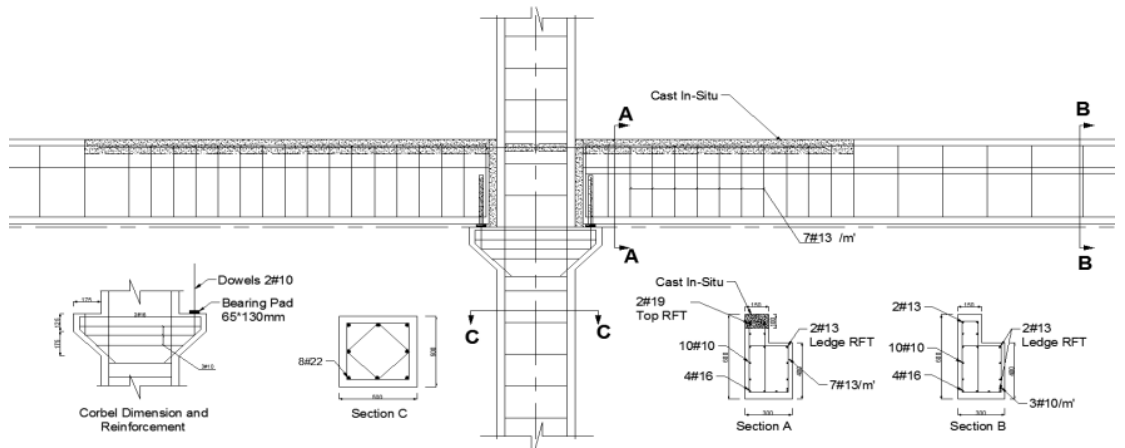

Figure 6: Ordinary moment frame connection (OMC).

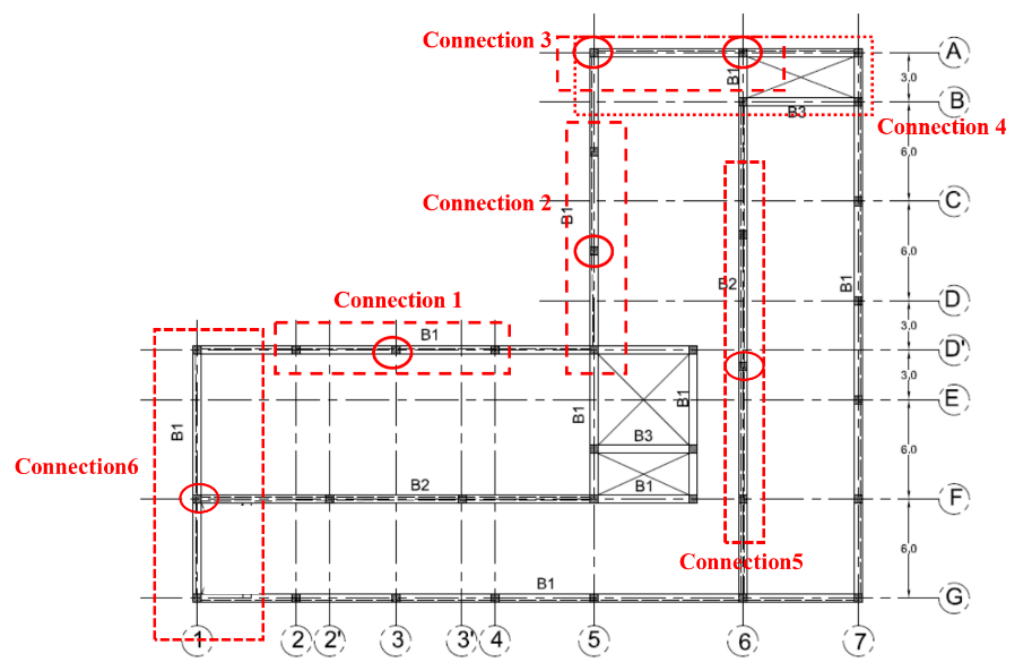

Figure 7: Prototype structural plan with the column removal scenarios. 

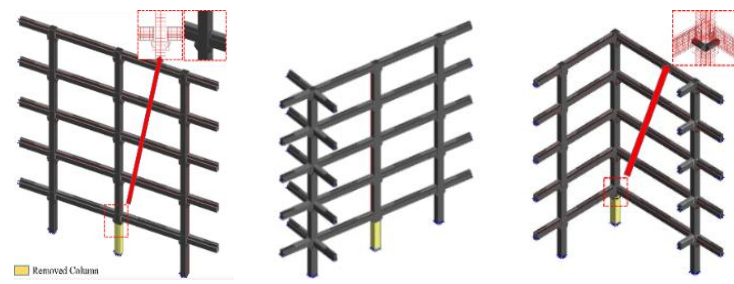

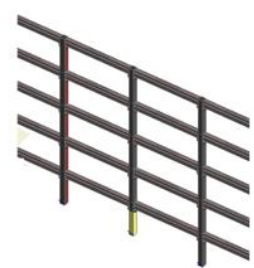

Connection 5

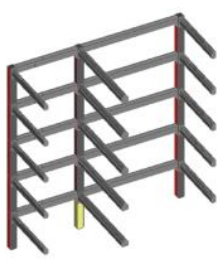

Connection 6

Connection 1 Connection $2 \quad$ Connection 3
Figure 8: ELS models for the studied connections.

\section{Case study}

A five-story prototype precast structure with $3.5 \mathrm{~m}$ floor height is designed according to the ACI and PCI [16]. One system is considered in the study which is the ordinary moment frame systems. The frames are designed to resist only the gravity loads using ordinary moment connections .Six column removal scenarios with different locations are presented in this paper.

\subsection{Prototype structure description}

The floor consists of slabs, L- beams placed at the structure perimeter and inverted T-beam used for the intermediate beams. All columns are of the same dimensions and same reinforcement. The Concrete compressive strength used is $40 \mathrm{MPa}$ and the reinforcement steel yield strength used is $420 \mathrm{MPa}$. Some parts in the designed connections are left hollow in order to pour cast in situ concrete to insure full connectivity between the main structural elements.

\subsection{Beam to column connections}

$\mathrm{RC}$ corbel beam to column connection is adopted as shown in the reinforcement detailing in Figure 7. All beams and columns in the ordinary moment frames are designed under gravity loading. A $100 \mathrm{~mm}$ at the beam top is kept open, with holes in the column for the addition of the top reinforcement. The top additional reinforcement is extended with a certain length to insure enough anchoring in the cast is situ concrete. Dowels are embedded in the beam bottom side in a gap before it is filled with cast in situ concrete.

\subsubsection{The Analytical Modeling}

Edge, exterior and interior column's removal is presented in this study as shown in Figure 8. The slab loads are applied directly on the precast beam without taking the slab model into consideration. A detailed modeling of the steel reinforcing bars and concrete with the selected material properties are defined in the ELS environment. The ground floor columns are assumed fixed to foundation.

Dynamic analysis is carried out with a demolition scenario of the selected column over a time duration of 1 second with a time step of 0.001 seconds. Connection 1 is an in-plane connection connecting two $6 \mathrm{~m}$ span beam with L- shape cross section. Connections 2 is same as connection 1 except that one of the beam's ends is connected out of plane with $\mathrm{L}$ and rectangular cross section beams. Connection 3 is a corner connection connecting two $6 \mathrm{~m}$ and $9 \mathrm{~m}$ span beams perpendicular on each other. Connection 4 is connecting two $6 \mathrm{~m}$ and $9 \mathrm{~m}$ span L-beams in plane and one rectangular beam of $3 \mathrm{~m}$ span out of plane with a column at a distance $3 \mathrm{~m}$ close to the connection. Connection 5 is connecting two interior inverted $\mathrm{T}$ beams of $8 \mathrm{~m}$ span. Connection 6 is connecting three beams, two are in plan with L-shape cross section and one inverted T-beam perpendicular to it without any columns close to the connection.

\subsubsection{Numerical Results}

For the main structural elements, deflection, rotation and the axial forces of beams as well as the axial forces in columns are obtained. For the stresses in dowels connecting beams to RC and the top reinforcement are calculated. 
Total collapse is reported for all the connections except in connection 4. Crack initiation and failure started at the connections at the other end of the beam away from the removed column as shown in Figure 10, cracks are indicated by yellow springs. The dowels and the top reinforcement of the other beam end fractured earlier than the dowels and the top reinforcement at the removed column connection.

To overcome the collapse that encountered in the studied connections a connection enhancement technique is suggested, designed and studied under the same column removal scenarios for the six studied connections.

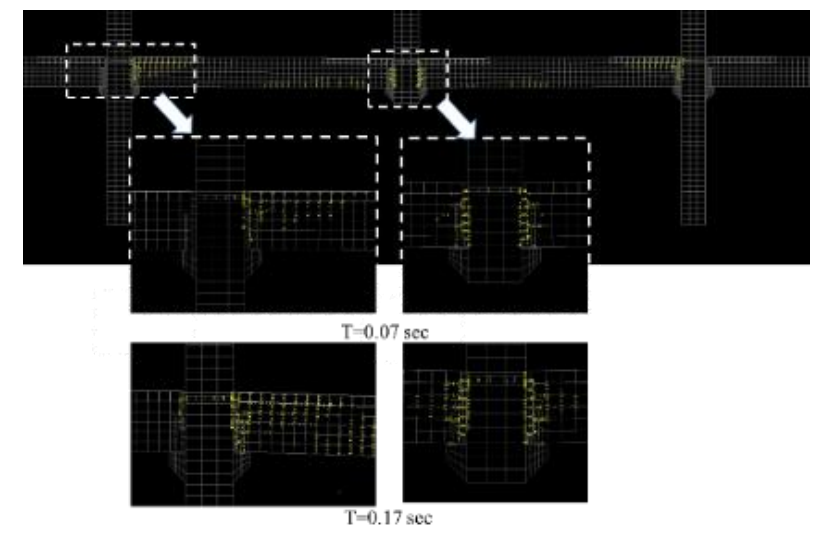

Figure 9: Crack propagation.
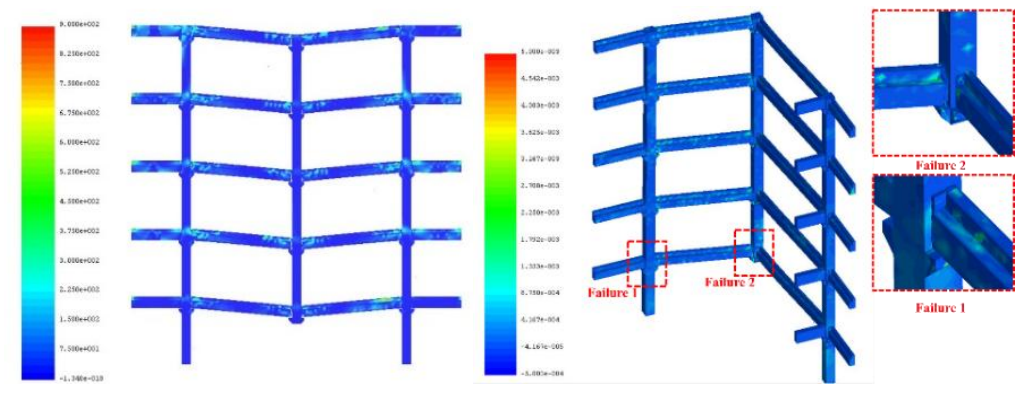

Figure 10: Stress contours for connection 1 and connection 3

\subsubsection{Proposed Enhanced Design}

From the analysis and the observation of the connection failure mode a suggested enhancement is adopted. To overcome the failure occurred in the middle connection of the removed column a steel $\mathrm{L}$ shape angle with bolts is designed and placed to connect the beam bottom with the column side, the main function of the steel angle with the bolts is to resist the large positive bending moment occurred due to the abrupt change in the beam span due to the column removal. As shown in Figure 11, the side bolts are designed to resist tension forces due to the applied bending moment and the vertical bolts are designed to overcome shear forces form the same bending moment. For the connections at the other beam end, an increase of the top reinforcement is suggested to withstand the axial tension force that occurred due to the high catenary action after the beam lost its stability in bending and worked as a tie member. The mentioned enhancement are applied at the middle connection and the other beam end connections.

All the connections are remodelled and analysed after applying the suggested enhancement. All results are obtained and compared to the results before enhancement.

\subsubsection{Results of Proposed Design}

As mentioned before connection 4 will be considered out of the enhancement study due to its ability to overcome the column loss. For connection 1 and 2 , the enhancement technique worked to prevent the connection from collapse due to the column removal, but shear failure took place in the beam itself, this failure can be resisted when considering the slab contribution. For connection 3 all the suggested enhancement techniques didn't work. The 
enhancement in connection 5 and 6 prevented the failure of the connections at the sides, but the middle connection encountered some local failures in the Reinforced concrete corbel at the location of the bolt embedment. This can be due to the fact that the inverted $\mathrm{T}$ beam is subjected to heavy loads, as a result the slab contribution is a must to see the overall behaviour of the connection before and after enhancement.

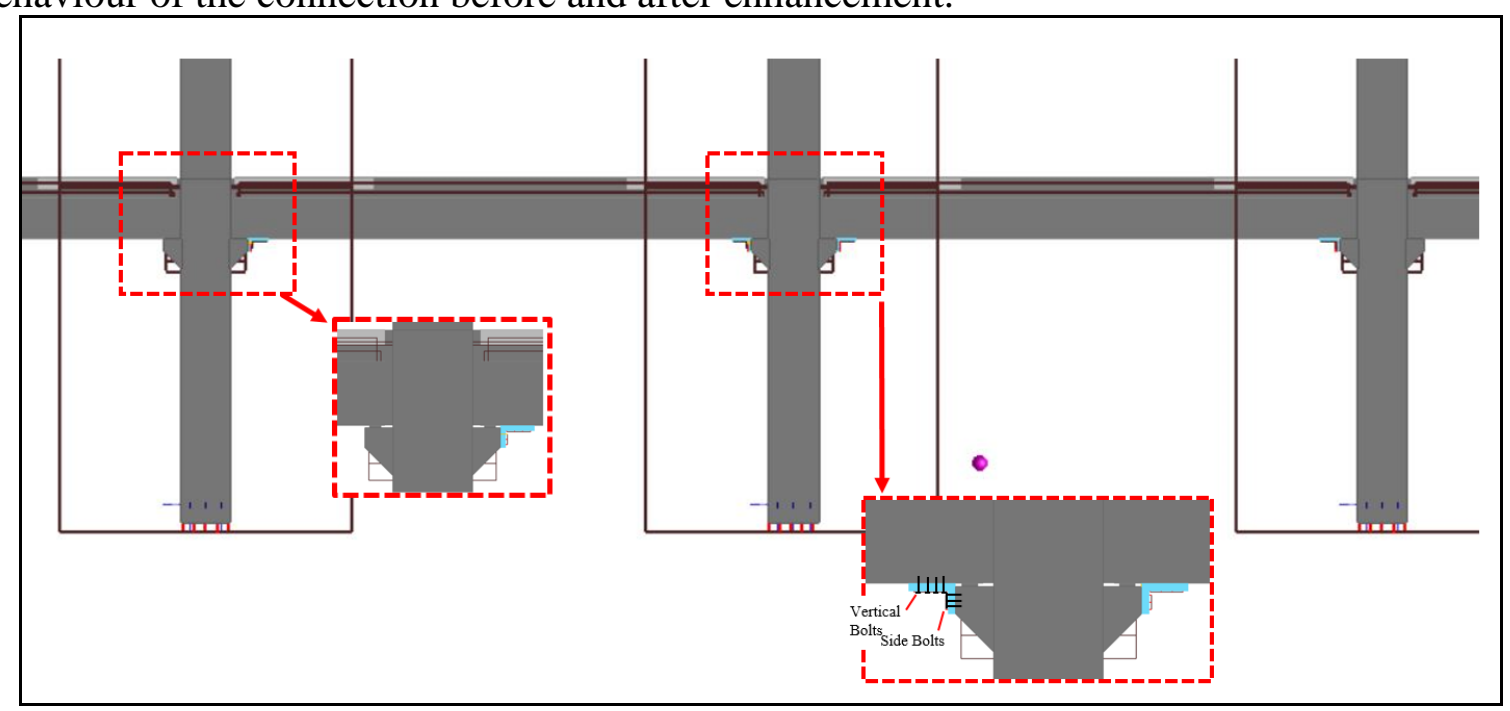

Figure 11: Enhancement Details

\subsubsection{Beam deflection and rotation}

For connection 1,2,5 and 6 the central deflection is calculated before and after enhancement, from Figure 12, it is obvious that the central deflection is reduced to around $43 \%$ after enhancement. For connection 4, the middle connection is dropped after column removal and vibrated with a maximum deflection of $20 \mathrm{~mm}$. As a result of no enhancement is suggested.
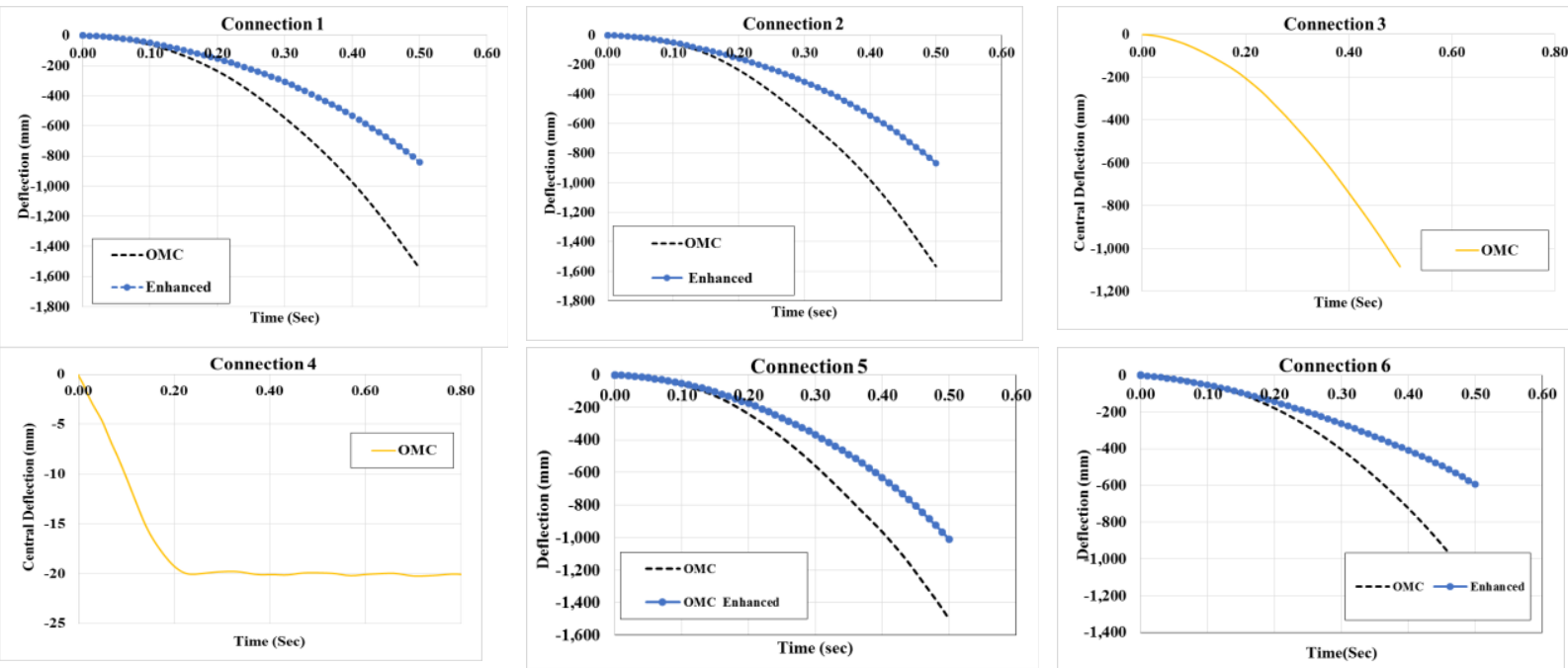

Figure 12: Beam deflection versus time. 
4.2.2.2 Beam axial force Due to the column removal, beams encountered two consecutive actions, the first is the compression arching effect that took place due to the in-plane restrain of the column to the beams, once the beam lost its capacity in resisting high compressive stresses the centenary action took place. The beam work as a tie member depending on the top reinforcement placed at the beam column connection.

Connections 1,2, 5 and 6 encountered the mentioned behaviour due to the in-plane beam alignment while in connection 3 , the absence of this behaviour is clear due to the fact that the connection between two beams and the removed column are perpendicular to each other and not restrained in-plane. For connection 4, the beam encountered initial tensile stresses due to the normal loading and then high constant compressive stresses.

After the enhancement, connections 1 through 6 (except connection 4) encountered a major change in the beam behaviour. From Figure 13, the compression arching of the beam is increased due to the increase in the beam capacity to overcome compressive stresses, as well as increasing the time period of the compression arching before transforming to the catenary action.
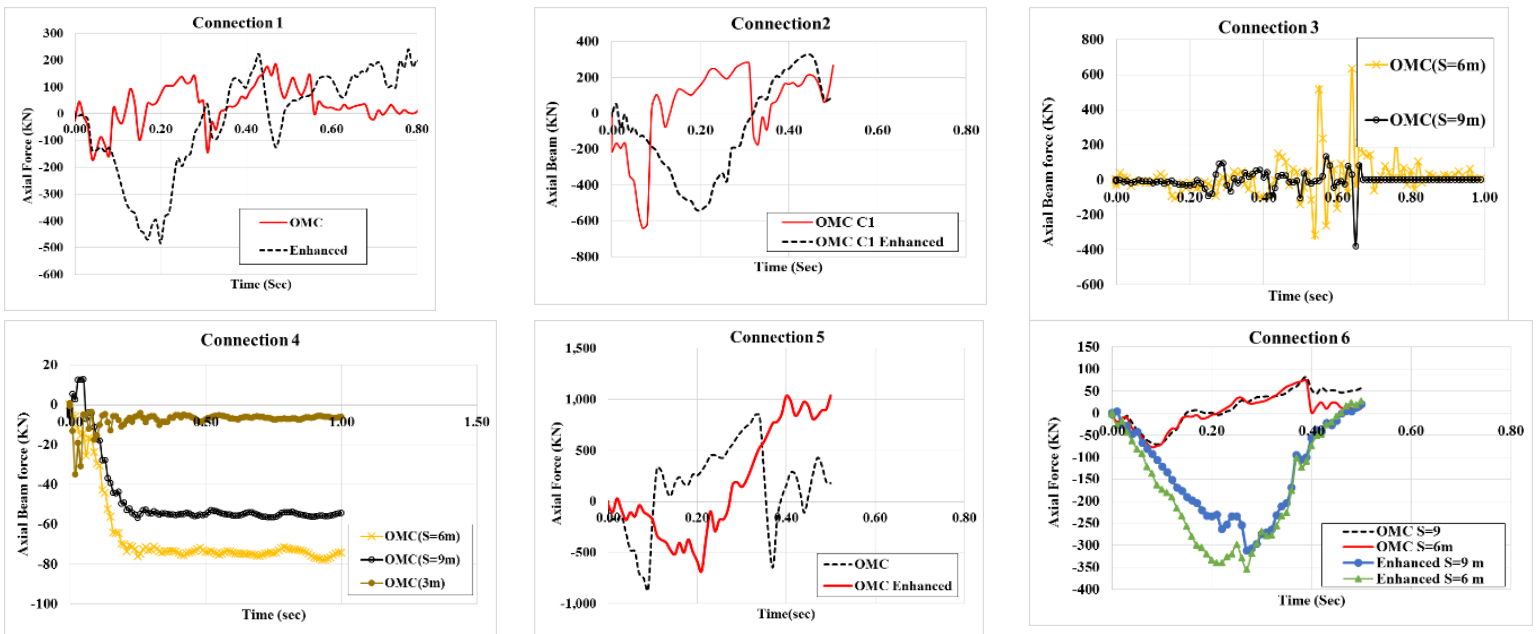

Figure 13: Beam axial force versus time.

\subsubsection{Reinforcement stresses}

Normal stresses is observed in both dowels and the top reinforcement placed at the connection. It is observed from Figure 14 that the side dowels suffered from two actions, the first action is compressive stresses due resisting the vertical downward movement of the beam due to column loss, but once the dowels of the middle connection reaches yield, the side dowels suffered from high tensile stresses to resist the rotation at the beam end due to high deformation till it fractures.

High tensile stresses occurred in the dowels of the middle connection till failure. This is due to the high contribution of the dowels in resisting the large deformation due to the column removal.

For connection 4 , it is observed that all the dowels at the sides for the three connected beams suffered from high compressive stresses, while dowels at the removed column connection suffered from high tensile stresses without any fracture of both dowels. The tensile stresses of dowels in the $3 \mathrm{~m}$ span is high compared to the other dowels, it can be concluded that the $3 \mathrm{~m}$ span beam is the main beam that resisted the connection collapse due to the column removal. After enhancement, it is noticed in connections $1,2,5$ and 6 that the contribution of the dowels is decreased severely as shown in Figure 14.

It is observed that the top reinforcements at the sides suffered from high tensile stresses and failed at the end due to the high catenary action. For the top reinforcement at the middle connection at the removed column, the same behaviour of the compression arching and the catenary action is observed but in terms of stresses. No failure is observed in the top reinforcement at the middle connection. The top reinforcement in connection 3 didn't shown any main contribution in resisting the failure due to the column removal as shown in the below chart. For connection 4, the top reinforcement contributed mainly in resisting the failure by subjecting to high tensile stresses. 
The enhancement technique prevented the top reinforcement at the sides from fracture. The top reinforcement in the middle suffered from compressive stresses only due to resisting the high bending moment at the middle span.
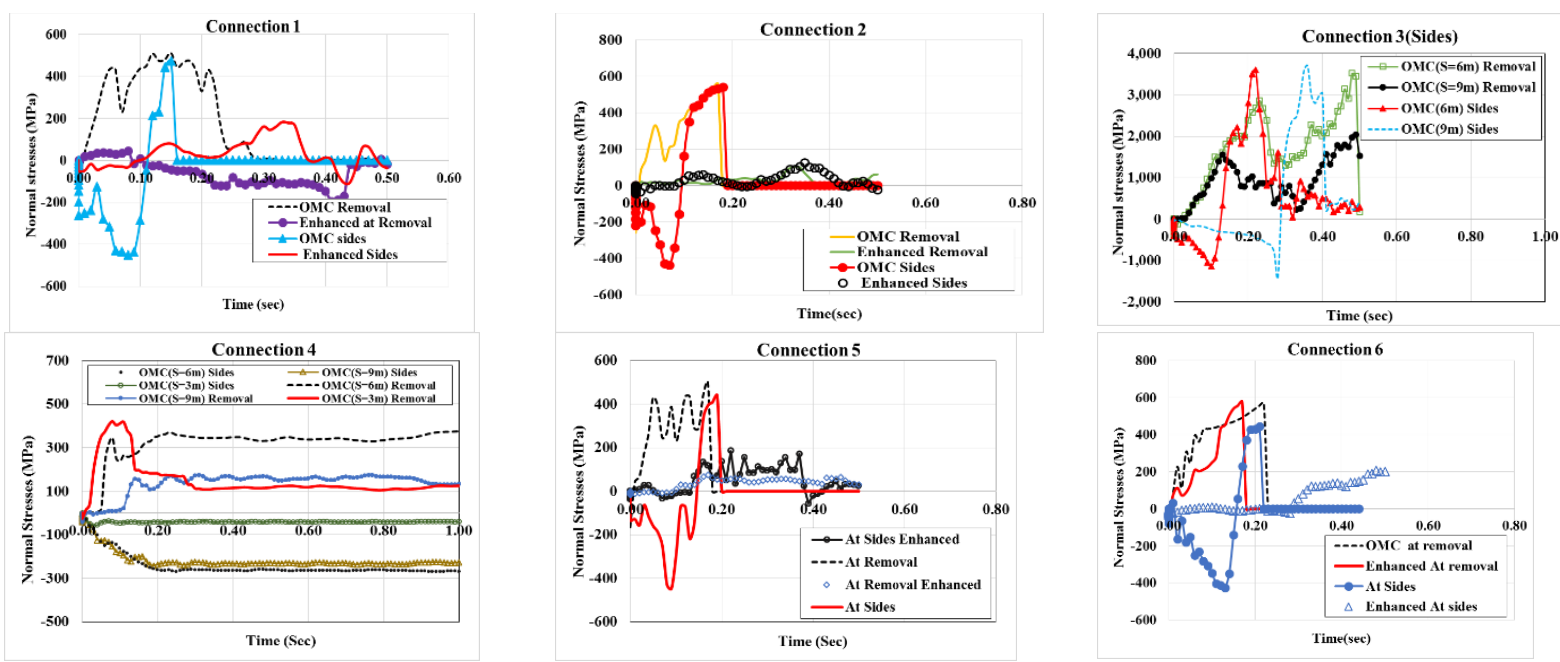

Figure 14: Dowels normal stresses versus time.

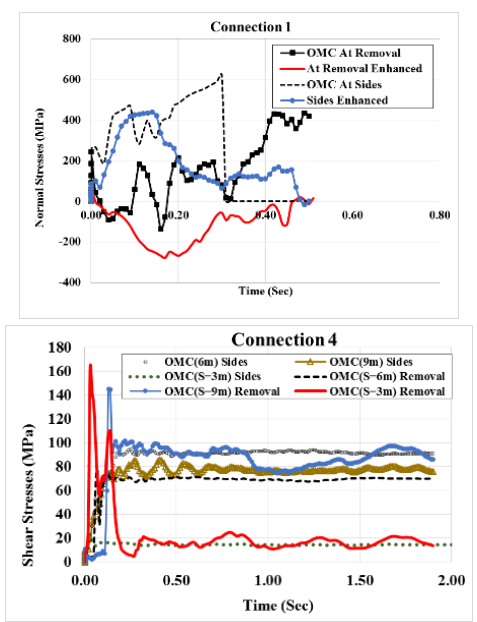

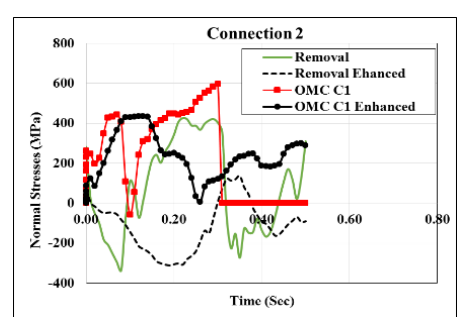

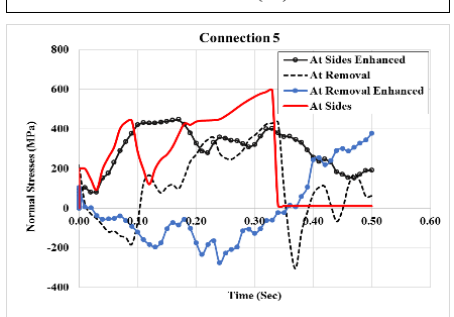

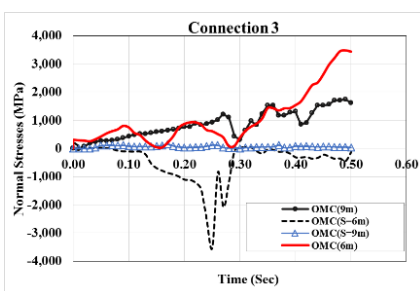

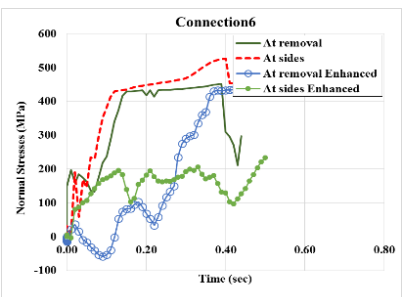

Figure 15: Top reinforcement normal stresses versus time.

\section{5-CONCLUSION}

Applied Element Method was proven to effectively analyze the precast connection subjected to column removal. It is found that the ordinary moment connection cannot resist the column removal scenario in most cases except in connection 4(An exterior connection connecting three beam, two beams have the same alignment while the third beam is perpendicular to it, and supported with a column at a distance $3 \mathrm{~m}$ from the connection). It was concluded that many parameters need to be considered in the study and the design to overcome connection failure;

- In all connections the top reinforcement at the sides failed due to column removal, as an enhancement suggestion, an increase of the top reinforcement to overcome the high tensile stresses is proposed.

- For the case where the connection failed in the middle (under the removed column), many approaches are evaluated. The only solution worked is strengthening the connection using steel angle with bolts designed to resist the high bending moment occurred.

- The suggested enhancement worked well for connections 1 and 2, and could successfully prevented the connection failure. Connection 3 failed, although many 
approaches are used beside the steel and the bolts, this can be due to the cantilever behavior and the large deformations of the two beams that are perpendicular due to losing the main supporting system without having any other element to restrain its deformation. The design enhancement worked in the sides of connection 5 and 6 with some local damage in the reinforced concrete corbel at the middle. It can be concluded that due to the heavy loads on the inverted $\mathrm{T}$ beam with the large span after column loss, lead to the failure despite of the enhancement provided. Connection 4 withstood the column failure due the contribution of the dowels as well as the contribution of the top reinforcement in resisting the failure.

- In connection 1 and 2, failure took place at the beam itself due to shear, while the side and the middle connection remained stable. So it can be concluded that taking the slab contribution into consideration will enhance the behavior of the connection under the column removal scenario. This can be applied and studied for connection 3, 5 and 6 to overcome the occurred failure.

\section{REFERENCES}

[1] Shi,F., "Assessment of progressive collapse requirements for precast concrete building," Lehigh University, 2011.

[2] Main, J. A., Bao,Y., Lew, H.S., Sadek,F., "Robustness of Precast Concrete Frames: Experimental and Computational Studies," National Institute of Standards and Technology, Gaithersburg, April , 2014.

[3] Nimse,R. B. , Josh,D. D. i, and Patel, P. V. , "Experimental Study on Precast Beam Column Connections Constructed Using RC Corbel and Steel Billet under Progressive Collapse Scenario," ASCE, no. Structures Congress 2015, pp. 1011-1117, 2015.

[4] Rohit B. Nimse ;Digesh D. Joshi ;Paresh V. Patel, "Behavior of wet precast beam column connections under progressive collapse scenario: an experimental study," International journal of Advanced Structural Engineering , no. 6, p. 149-159, 2014.

[5] ACI COMMITTEE, 318, Building Code Requirements for Structural Concrete (ACI 318 08) and Commentary, American Concrete Institute, 2008.

[6] Meguro; K., and Tagel-Din; H., "AEM Used for Large Displacement Structure Analysis," Journal of Natural Disaster Science, no. 24(1), pp. 25-342, 2003.

[7] H. Salem, A. El-Fouly, H. Tagel-Din, "Toward an economic design of reinforced concrete structures against progressive collapse," Engineering Structures, vol. 33(12), pp. 3341-3350.

[8] “www.appliedelementmethod.org," [Online].

[9] Tagel-Din;H. and Megur;K., "Applied Element Method for Simulation of nonlinear materials: theory and application for RC Structures in Structural Engineering," Earthquake engineering Japan Society for Civil Engineers (JSCE), no. 17(2), pp. 137$148,2000$.

[10] Meguro;K. and Tagel-Din;H., "Applied Element method for Structural analysis : Therory and application for linear materials in Structural Engineering," Earthquake Engineering , Japan Society for Cibil Engineers (JSCE), no. 17(1), pp. 21-35, 2000.

[11] Meguro; K., and Tagel-Din; H. , "Applied Element Simulation of RC Structures under Cyclic Loading," AASCE, no. 127(11), pp. 1295-1305, 2001.

[12] O. H. 1. Maekawa K, "The deformational behavior and constitutive equation of concrete using the elasto-plastic and fracture model," Faculty Eng Univ Tokyo,37(2), p. 253-328., 1983.

[13] Ristic D, Yamada Y, Iemura H., "Stress-strain based modeling of hysteretic structures under earthquake induced bending and varying axial loads," Research report No. 86-ST01, School of Civil Engineering, Kyoto University, 1986.

[14] Bathe,K., "Solution of equilibrium equations in dynamic analysis," Englewoods Cliffs, NJ: Prentice Hall, 1982.. 
[15] A.Chopra, "Dynamics of Structures: Theory and Applications to Earthquake Engineering"," Prentice Hall, Englewoods Cliffs, N.J,, 1995.

[16] PCI Industry Handbook Commitee, , PCI design Handbook precast/prestressed Concrete, Chicago, Illinois: Prototype Type structure description, 2004.

[17] Hartmann, D., Breidt, M., Nguyen, V., Stangenberg, F., Hohler, S., Schweizerhof, K., Mattern, S., Blankenhorn, G., Moller, B., and Liebscher, M. (2008)," "Structural Collapse Simulation under Consideration of Uncertainty Fundamental Concept and Results," Computers and Structures, no. 86, p. 2064-2078, 2008.

[18] "www.extremeloading.com Extreme Loading of Structure software Manual.," [Online]. 